San Jose State University

SJSU ScholarWorks

Master's Theses

Master's Theses and Graduate Research

Summer 2021

\title{
Changes in Allochronic Breeding Populations of Pink Salmon (Oncorhynchus Gorbuscha) of Prince William Sound, Alaska
}

Claire Dormody

San Jose State University

Follow this and additional works at: https://scholarworks.sjsu.edu/etd_theses

\section{Recommended Citation}

Dormody, Claire, "Changes in Allochronic Breeding Populations of Pink Salmon (Oncorhynchus Gorbuscha) of Prince William Sound, Alaska" (2021). Master's Theses. 5198.

DOI: https://doi.org/10.31979/etd.yhyn-z9wj

https://scholarworks.sjsu.edu/etd_theses/5198

This Thesis is brought to you for free and open access by the Master's Theses and Graduate Research at SJSU ScholarWorks. It has been accepted for inclusion in Master's Theses by an authorized administrator of SJSU ScholarWorks. For more information, please contact scholarworks@sjsu.edu. 


\author{
A Thesis \\ Presented to \\ The Faculty of the Department of Environmental Studies \\ San José State University
}

In Partial Fulfillment

of the Requirements for the Degree

Master of Science

by

Claire Dormody

August 2021 
(C) 2021

Claire Dormody

ALL RIGHTS RESERVED 
The Designated Thesis Committee Approves the Thesis Titled

TRENDS IN ALLOCHRONIC BREEDING POPULATIONS OF PINK SALMON (ONCORHYNCHUS GORBUSCHA) OF PRINCE WILLIAM SOUND, ALASKA

\author{
by \\ Claire Dormody \\ APPROVED FOR THE DEPARTMENT OF ENVIRONMENTAL STUDIES \\ SAN JOSÉ STATE UNIVERSITY
}

August 2021

Kathryn Davis, Ph.D. Department of Environmental Studies

Lynne Trulio, Ph.D. Department of Environmental Studies

Rachel Lazzeri-Aerts M.S. Department of Environmental Studies 


\begin{abstract}
TRENDS IN ALLOCHRONIC BREEDING POPULATIONS OF PINK SALMON (ONCORHYNCHUS GORBUSCHA) OF PRINCE WILLIAM SOUND, ALASKA
\end{abstract}

\author{
By Claire Dormody
}

Prince William Sound, Alaska is home to one of the largest pink salmon (Oncorhynchus gorbuscha) fisheries in the world. Salmon populations there have been fished commercially for over a century, and the State's documentation of commercial fishing provides a valuable dataset in order to examine abundance trends of species in this region. For this thesis research, I analyzed the fluctuations in abundance and isolated even year and odd year breeding populations of pink salmon to assess whether there is a numerical discrepancy between pink salmon that spawn in odd years and the population that spawns in even years. Analysis of these two populations showed differences in the abundance of pink salmon in even breeding years when compared to odd years. This research also indicated that there is a growing difference in the rate of increase of the odd and even year populations over the fifty-year span, 1968-2018. Increasing instability and differences between the two breeding populations may be the result of factors such as changing ocean temperatures, human intervention by way of fishing and artificial stock enhancement, and instances of environmental disaster and pollution in the region. Future research should investigate factors that may be resulting in these population differences. 


\section{ACKNOWLEDGMENTS}

I would like to express my gratitude to my advisor, Dr. Kathryn Davis, and my thesis committee members Professor Rachel Lazzeri-Aerts and Dr. Lynne Trulio for their continued support and patience. To my mother and father, Nancy and Michael, for their fostering my love of the oceans and of further learning. And to my partner, Mary, and my wonderful friends, Leigh Anne, Kassandra, and Zeek who encouraged me throughout my studies.

Additionally, I want to acknowledge and thank the Alaska Department of Fish and Game for their commitment to documenting the recent history of fishing in the state, and the Alaska Native community that has relied on and respected the wild salmon populations for centuries. 


\section{Table of Contents}

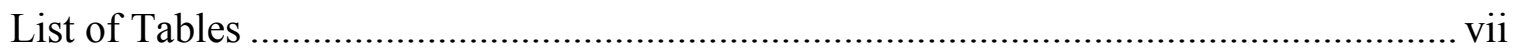

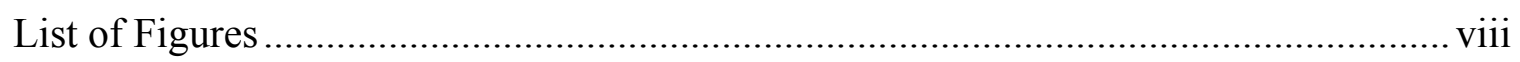

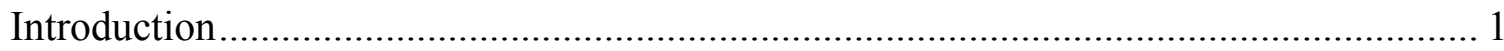

Literature Review ............................................................................................. 2

State Salmon Fisheries ............................................................................... 2

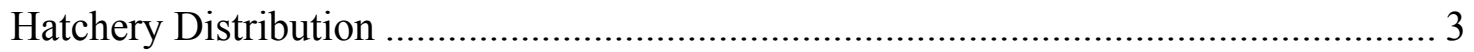

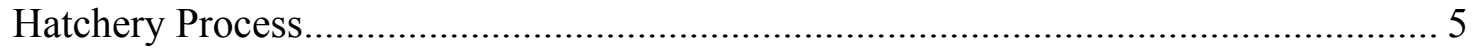

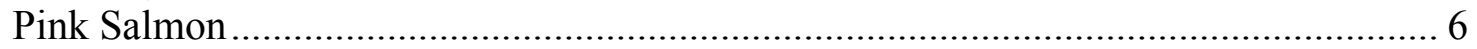

Problem Statement .......................................................................................... 9

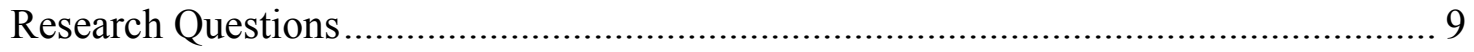

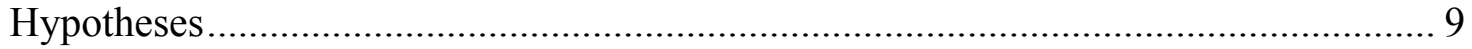

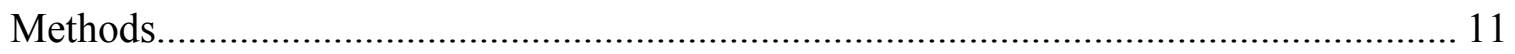

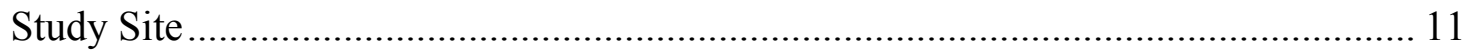

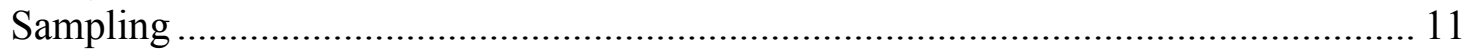

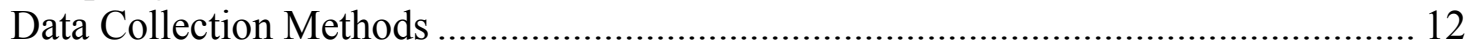

Catch as Abundance Index ..................................................................................... 14

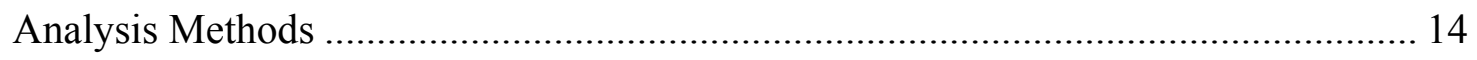

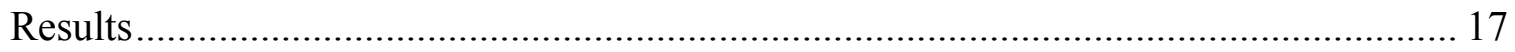

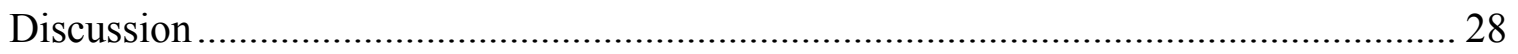

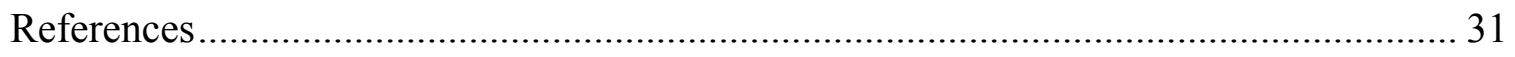




\section{LIST OF TABLES}

Table 1. Slopes of the cumulative sum lines in the datasets..................... 23 


\section{LIST OF FIGURES}

Figure 1. Prince William Sound, located in the Southcentral fishing area, and the eleven subdivided districts (AKDFG 2018).

Figure 2. An example of Alaska Department of Fish and Game catch reports, this one from 2017, in number of fish caught and sold (Vega et al. 2017).

Figure 3. The full dataset of abundance indices, where even years are represented in blue and odd years are represented in red.

Figure 4. The abundance indices from 1969 to 2017, with trendlines showing the overall increase in million of fish caught.

Figure 5. Percent change in the raw data of the odd year broodline, negative values indicating a downward trend in abundance and positive values indicating growth.

Figure 6. Percent change in the raw data of the even year broodline, negative values indicate a downward trend in abundance and positive values indicate growth. 1972 was a record low year with a catch of 57,000 fish.

Figure 7. Percent change values for the dataset from 1968-2018, odd years typically marking a large increase from the prior even year.

Figure 8. Side by side view of the differenced broodline datasets, now stationary, achieved by subtracting the previous year from the current one.

Figure 9. The cumulative sum of the abundance index, achieved by adding each year to the sum of the previous.

Figure 10. The cumulative sums of the even broodline in blue and the odd broodline in red.

Figure 11. The cumulative sums of the even, in blue, broodline and the odd, in red, broodline, including trendlines representing the rate of change. ...

Figure 12. Autocorrelation of the abundance dataset at lag 1, for the first 18 years. Values in the data after this become even smaller and insignificant.

Figure 13. The results of autocorrelation tests on even data, where the dotted blue lines represent a 0.05 confidence interval.

Figure 14. Autocorrelation of odd year raw data, where the dotted blue lines represent a 0.05 confidence interval. 


\section{Introduction}

The pink salmon (Oncorhynchus gorbuscha) fishery in Prince William Sound, Alaska is a large and economically important industry in the region. Characterizing and understanding population trends for this species is essential, not only to maintaining the species, but also supporting the livelihoods of people dependent on the fishery. Existing

fishing totals maintained by the State of Alaska, when used as an abundance index of the salmon population, provide a dataset to analyze shifts in population and survival to maturity over many years of human intervention in the region. Pink salmon are divided into two populations or broodlines, that breed separately - one in even years and one in odd years. Comparing the abundance indices for each broodline provides concrete evidence of changes in the populations relative to each other. Changes in the patterns of the two salmon populations may herald not only environmental instability, but also cause similar instability in the community that relies on the fishing industry for income and food security. 


\section{Literature Review}

State Salmon Fisheries

The salmon fishing industry in Alaska is a significant economic force, not only in the state, but also in the Pacific Northwest and globally. Seafood harvested from Alaskan waters is distributed across the world and throughout the U.S. market, accounting for $50 \%$ of the U.S. wild fish landings and making the waters off the coast of Alaska a valuable resource (Loring 2013). The average dollar value of seafood harvested from Alaskan waters in a year comes to around $\$ 5.2$ billion based on 2015 and 2016 reports. Of this, salmon catches were responsible for $\$ 628$ million of the sales, not including further circulation of fishery income or state and federal government fees (Botz and Russell 2017).

Alaska state fishing waters are divided into different regions (Figure 1). Furthest north and west, the Arctic-Yukon-Kuskokwim fishing region includes the coldest waters in the state (Buklis 1999). To the southwest is the Westward or Aleutian region, named for the Aleutian Islands. The Southeast region is located to the east of the Gulf of Alaska, west of Juneau. Finally, the South Central, or Central, region includes Bristol Bay, Cook Inlet, and Prince William Sound, some of the most productive salmon fisheries in the world (Heard 2001). Each of these regions is further divided into management districts, which are opened or closed throughout the season as the fish runs allow. All districts are managed with the "maximum sustainable yield" principle in mind, as stated by the Alaska Department of Fish and Game. This principle dictates that fishing stocks should 
be maintained at "maximum production of food from the sea on a sustained basis year after year" (Chapman 1949).

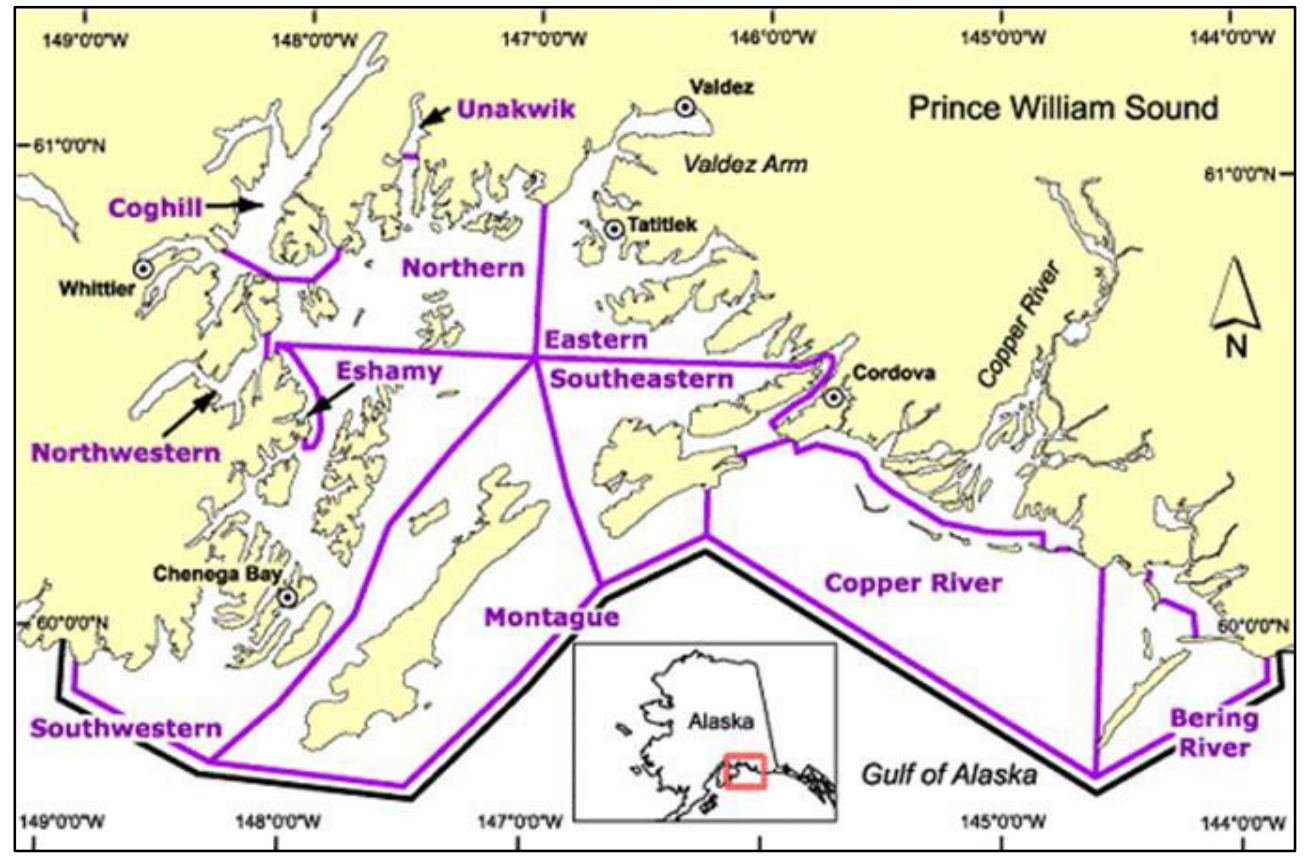

Figure 1. Prince William Sound, located in the Southcentral fishing area, and the eleven subdivided districts. (AKDFG 2018)

\section{Hatchery Distribution}

The Alaska salmon industry has been a commercial power since the $1800 \mathrm{~s}$, and the first hatchery intended to bolster the population was constructed in 1892 on Etolin Island in order to address concerns of population decline, assumed to be caused by overfishing (Heard 2012). Initially, the focus was on production of sockeye salmon (Oncorhynchus nerka), and 12 of these hatcheries were constructed, including some owned and operated by the US Bureau of Fisheries (Hillborn and Eggers 2000). However, the impact was not as successful as the agency had hoped and most of the hatcheries were closed by the 1930s (Heard 2012). Salmon harvests were high following the closures, harvesting solely 
wild stock runs. But by the 1970s, harvests were facing record lows (Hillborn et al. 2003). Attempts in the 1940s and 1950s to control overfishing and mitigate population decline, such as banning fish traps, were unsuccessful and the overfishing combined poorly with perceived environmental changes to create record population lows (Heard 2012). This record decline prompted a resurgence of hatchery efforts in the state of Alaska, focusing largely on the production of chum (Oncorhynchus keta) and pink salmon (Schoen et al. 2017). In 1971, the Division of Fisheries Rehabilitation, Enhancement, and Development (FRED) was created within the Alaska Department of Fish and Game (Frenette and Lum 2010). FRED was responsible for maintaining and providing increased funding to single-species hatcheries devoted to the management of the salmon population (Hillborn et al. 2003). FRED provided funding for state run hatcheries, which, aided by the 1974 Private Nonprofit (PNP) Hatchery Act, permitted expansion into new locations (Stopha 2016). The PNP Hatchery Act allowed private companies or associations to operate hatcheries contributing to common property waters. Additionally, private hatchery operations were permitted to recover operating expenses with fish sales (Heard 2012). This is referred to as "cost recovery" fishing and allows hatcheries to contract fishermen for a certain dollar amount of catch. Fishermen are granted priority access to fishing grounds until the hatchery goals are met, and sales recoup hatchery operating costs. Currently, the PNP hatcheries make up the majority of the hatchery operations in the state, funded first by sales of cost recovery fish, of excess roe harvested that is not needed for breeding, and finally by state and federal grants (McDowell 2018; Stopha 2016). 
Most remaining hatcheries are clustered around the Central and Southeast regions (Heard 2001). The Southeast Alaska fishing zone, SEAK, has two research hatcheries and 15 production hatcheries, providing mainly chum salmon as well as sockeye, Chinook (Oncorhynchus tshawytscha), and pink salmon (Heard 2012). The Central region contains Prince William Sound (PWS) and the world's largest pink salmon hatchery operation (Tillotson, Hillborn, and Amoroso 2017). Ten hatchery facilities are still operational in the region, three of which focus on pink salmon output (Hillborn and Eggers 2000). The concentration of hatcheries is distributed in such a way as to target most of the commercial fishing fleet in the Gulf of Alaska, though not necessarily most independent fishermen (Heard 2012; Loring 2013). Of eight PNP hatchery groups, five currently produce salmon stocks for CCP fisheries and are organized as aquaculture associations, Prince William Sound Aquaculture Corporation (PWSAC) being the one local to Prince William Sound. These aquaculture associations receive tax revenue from the Alaska Department of Revenue to additionally fund operating costs (McDowell 2018). Grant money is also available to associations like PWSAC via state, local, and federal associations (McDowell 2018).

Hatchery Process

During each year's salmon run, hatcheries contract fishermen to harvest their allotment of brood stock, from which the hatchery harvests eggs and sperm. They then fertilize and incubate the next season's crop of fish. Hatcheries are permitted a certain number of eggs to harvest and fertilize which varies depending on the size of the facility (Heard 2012). These numbers are estimated with the understanding that fertilization is 
not one hundred percent, and mortality rates of juvenile fish are high upon release, so the returning fish populations will be much lower (Stopha 2016). The purpose of hatchery operations is to bolster wild fish populations by overcoming the even higher natural mortality that wild-spawning juvenile fish experience. Hatcheries do not select for any specific traits such as longevity or size, and while the hatchery fish are considered distinct from wild-spawning, they can be marketed identically as wild-caught salmon due to their growth to maturity in common property waters (Stopha 2016). However, hatchery fish are also distinct from farm-raised fish, which must be raised to market weight in captivity (Stopha 2016).

Since the introduction of modern hatchery practices, the pink salmon catch in PWS has increased dramatically. Wild pink salmon runs in PWS vary between 2.2 million and 19.6 million fish, in state-run surveys collected since 1977 (Bue et al. 1998). The combination of high-volume hatchery production alongside existing wild populations has led pink salmon harvests to increase to over 35 million fish in recent years, with an all time high of 76 million in 2013 (Tillotson, Hillborn, and Amoroso 2017). In PWS the three major hatcheries producing pink salmon are Armin F. Koernig, Wally Noerenberg, and Cannery Creek, which are permitted annually for broodstock harvest of 162 million, 148 million, and 187 million pink salmon eggs respectively (PWSAC 2018). Pink Salmon

There are five species of Pacific salmon native to Alaska. Of these, pink salmon are the smallest and the shortest lived. They are anadromous fish, which migrate from the ocean where they live out their lives into freshwater streams to spawn (Irvine et al. 2014). 
Spawning typically occurs in the fall, and juvenile fish hatch and grow in freshwater streams until spring when they migrate to open water. Once attaining open ocean, fish live out a two-year life cycle before returning to spawn. Due to this time frame, pink salmon are classified as an allochronic species, meaning populations share a habitat but are genetically separated by breeding season (Alexander and Bigelow 1960; Tarpey et al. 2017). This phenomenon is rare in vertebrate species and provides an interesting perspective to analyze differences within the two populations, or broodlines, of the species (Irvine et al. 2014; Taylor and Friesen 2017). Research has shown that even-year populations may be lower in total number of fish than odd-year populations depending on the region, though this has not been assessed in Prince William Sound (Irvine et al. 2014; Tarpey et al. 2017). Broodlines from different years, even those returning to the same spawning stream, exhibit more genetic differentiation than fish from same-year broodlines in different habitats (Tarpey et al. 2017). Pink salmon runs with higher total numbers often exhibit lower individual body weights, while lower total numbers exhibit higher individual weights, due to decreased competition for resources (Wertheimer et al. 2017).

No other Pacific salmon species experiences this breeding isolation, as they all have longer lifespans and reach maturity in overlapping cycles. Though the phenomenon has been analyzed in some regions outside of Prince William Sound, no consensus has been reached yet as to the source of the population size differences. Theories include overfishing, climate change, and resource competition as possibilities for the discrepancy, but so far, no explanation can be isolated (Irvine et al. 2014). Furthermore, the research 
confirming the existence of this gap in population numbers does not often address change in the phenomenon over time. 


\section{Problem Statement}

The magnitude of the discrepancy between pink salmon broodlines in Prince William Sound is largely unstudied as is whether any discrepancies may fluctuate over time.

Record low years such as the 2016 season have necessitated disaster relief measures for the fishery and those who rely on it, including $\$ 32,044,231$ to be distributed to participants and another $\$ 17,700,062$ to processors (AKDFG 2018; Botz and Russell 2017). Meanwhile, the odd-numbered years 2013 and 2015 had all time high records for the pink salmon fisheries in PWS (Botz and Russell 2017).

The purpose of this thesis research was to characterize the population differences in the even-year versus the odd-year broodlines of the Prince William Sound region and to determine if and how the population differences might be changing over time. To address this goal, I assessed the following research questions and hypotheses:

Research Questions

RQ 1: Does the abundance of one broodline impact the other?

RQ 2: Are the odd and even year broodlines distinguishably different from each other? In what ways are they different?

RQ 3: Does one broodline exhibit dominance in the region?

RQ 4: How have the population trends of these two broodlines changed over time? Is there a growing discrepancy between odd and even year populations?

Hypotheses

H1: The even and odd year broodlines are not significantly different from each other.

$\mathrm{H} 1_{0}: \mathrm{A}=\mathrm{B}$. Data shift is equal to zero.

$\mathrm{H} 1_{\mathrm{a}}: \mathrm{A} \neq \mathrm{B}$. Data shift is not equal to zero. 
$\mathrm{H} 2$ : Annual abundance is not dependent on the previous year's abundance.

$\mathrm{H} 2_{0}$ : Data points at lag 1 do not exhibit serial correlation.

$\mathrm{H}_{2}$ : Data points at lag 1 are not independently distributed; they exhibit serial correlation. 


\section{Methods}

Study Site

According to the Alaska Department of Fish and Game, the Prince William Sound Management Area encompasses "all coastal waters and inland drainages entering the Gulf of Alaska between Cape Suckling and Cape Fairfield" (AKDFG 1985; Botz and Russell 2017). This zone is further subdivided into eleven districts; Coghill, Copper River/Bering River (two districts most often referred to together), Eastern, Eshamy, Montague, Northern, Northeastern, Southeastern, Southwestern, and Unakwik (Figure 1). These range from very large like the Copper River district, which spans more than 1,100 square miles, to very small such as the Bering River district, which is barely 200 square miles (Botz \& Russell 2017). Each district is managed individually for fishing and may be open or closed throughout the season as needed. As such, each district has its own total catch report compiled by Fish and Game, as well as being factored into the regional report for salmon catches made in Prince William Sound. Prince William Sound was selected as the research site because it is the location of the second largest pink salmon fishing operation in the world (Amoroso, Tillotson, and Hillborn 2017) Sampling

Prince William Sound is treated here as a single case study. Though each of the 11 districts may be individually sampled, the overlap of fish in each of these regions as well as the analysis of the overarching presence of pink salmon in PWS makes it impossible to treat each district as an individual sample. Salmon do tend to return to the streams they hatched in, or those nearby, but straying into other waters is common enough that the 
delineations between fishing zones do not guarantee an isolated population (Groot and Margolis 1991). Furthermore, the districts are not divided evenly in terms of size, spawning ground access, or hatchery use, so they would not provide equivalent or comparable conditions. Thus, yearly data for pink salmon for the entire PWS region were compared to each other.

Each year was compared to previous and following years, as well as averaged out with other years in that broodline for comparison. Data from 1968-2018 were compared for this study to answer questions for the two broodlines. Records before 1968 do exist within Alaska Fish and Game offices but are inconsistent and provide less useful data overall.

\section{Data Collection Methods}

Data collection and analysis was completed utilizing secondary data, gathered and compiled by the Alaska Department of Fish and Game. As the state's primary regulatory agency in the fishing industry, it maintains extensive records of fish harvests. Records from 2009 to the present are available online through the Fish and Game website. Earlier records must be accessed through the Department, by request. The oldest records remain in Fish and Game offices in hard copy. Records are available to the public at no cost. Fishermen are required to be licensed and permitted in the district they fish and must receive a fish tag for every catch that is sold (AKDFG 2018). These tags are issued and tracked by Fish and Game, providing a record of the season that is compiled into a yearly report of the pounds of fish of every species harvested in every region. Prince William Sound has its own report, broken down by species and then into each individual district 
(Figure 2). Commercial Common Property Fishery (CCPF) totals represent fish sold to independent processing companies, while hatchery totals represent fish sold as part of the cost-recovery system to recoup hatchery-operating costs (Vega et al. 2017). Both factor into the total catch of pink salmon. Each fishing year, the season beginning in late June and ending August or September, has a gross number of fish caught, which can then be used as a relative indicator of abundance (Campbell 2015). This method of research is common to fisheries studies, as independent surveys are expensive and time consuming, while anglers and commercial fishing vessel data are often already recorded (Pennington 1985).

\begin{tabular}{|lrrrrrr|}
\hline \multicolumn{7}{l}{ Table 1.-Preliminary Area E salmon harvest, 2017 (10/03/2017). } \\
\hline District & Chinook & Sockeye & Coho & Pink & Chum & Total \\
\hline Bering River & 36 & 2,593 & 118,172 & 105 & 14 & 120,920 \\
Copper River & 13,139 & 569,321 & 304,042 & 68,826 & 11,639 & 966,967 \\
Eastern & 60 & 15,024 & 46,041 & $17,671,121$ & 317,219 & $18,049,465$ \\
Northern & 8 & 16,925 & 12,401 & $7,330,193$ & 128,629 & $7,488,156$ \\
Coghill & 74 & 118,369 & 14,438 & $1,113,153$ & $3,036,549$ & $4,282,583$ \\
Northwestern & 2 & 20,564 & 1,341 & $1,451,741$ & 46,886 & $1,520,534$ \\
Eshamy & 89 & 620,999 & 4,077 & 350,317 & 120,221 & $1,095,703$ \\
Southwestern & 136 & 50,973 & 20,187 & $11,629,000$ & 446,044 & $12,146,340$ \\
Montague & 94 & 10,000 & 7,425 & $3,381,639$ & 539,333 & $3,938,491$ \\
Southeastern & 5 & 991 & 732 & 676,741 & 52,037 & 730,506 \\
Unakwik & 0 & $\mathbf{7 6 4}$ & 0 & 208 & 70 & 1,042 \\
\hline CCPF Total & $\mathbf{1 3 , 6 4 3}$ & $\mathbf{1 , 4 2 6 , 5 2 3}$ & $\mathbf{5 2 8 , 8 5 6}$ & $\mathbf{4 3 , 6 7 3 , 0 4 4}$ & $\mathbf{4 , 6 9 8 , 6 4 1}$ & $\mathbf{5 0 , 3 4 0 , 7 0 7}$ \\
\hline Hatchery & & & & & & \\
Solomon Gulch & 0 & 0 & 25,263 & $1,602,084$ & 0 & $1,627,347$ \\
Cannery Creek & 0 & 0 & 0 & 527,103 & 0 & 527,103 \\
Wally Noerenberg & 0 & 0 & 0 & $1,061,669$ & 723,981 & $1,785,650$ \\
Main Bay & 0 & 10,000 & 0 & 0 & 0 & 0 \\
Armin F. Koernig & 0 & 0 & 0 & $1,866,288$ & 0 & $1,866,288$ \\
\hline Hatchery Total ${ }^{\text {a }}$ & $\mathbf{0}$ & $\mathbf{1 0 , 0 0 0}$ & $\mathbf{2 5 , 2 6 3}$ & $\mathbf{5 , 0 5 7 , 1 4 4}$ & $\mathbf{7 2 3 , 9 8 1}$ & $\mathbf{5 , 8 1 6 , 3 8 8}$ \\
\hline PWS Total & $\mathbf{1 3 , 6 4 3}$ & $\mathbf{1 , 4 3 6 , 5 2 3}$ & $\mathbf{5 5 4 , 1 1 9}$ & $\mathbf{4 8 , 7 3 0 , 1 8 8}$ & $\mathbf{5 , 4 2 2 , 6 2 2}$ & $\mathbf{5 6 , 1 5 7 , 0 9 5}$ \\
Harvest & & & & & & \\
\hline
\end{tabular}

Figure 2. An example of Alaska Department of Fish and Game catch reports, this one from 2017, in number of fish caught and sold (Vega et al. 2017). 
Catch as Abundance Index

The purpose of the yearly catch data is to act as an abundance index for the population. While catch is not a perfect indicator of abundance, it is a reliable index that is used frequently within fisheries research. The collection of data by fisheries management organizations, in this case the Alaska Fish and Game Department, is large scale and long running, providing excellent datasets for analysis. As such, the method of catch-as-abundance can be seen throughout research such as in Irvine et al. (2014) and other works (Irvine and Fukuwaka 2011; Noakes and Beamish 2011; Radchenko et al. 2007). In the case of this research, the comparison of years with those alongside, as well as the comparison of rates of change of abundance presents no need for Catch Per Unit Effort calculations.

Analysis Methods

All statistical analysis was conducted using RStudio, version 1.3.1073. In order to address the research questions, I performed analysis on three data sets. The first encompasses the total catch each year from 1968 to 2018. From this dataset, two individual broodline datasets were isolated. Values recorded in even years and values recorded in odd years make up the even- and odd-year broodline data, respectively.

Because the series are not normally distributed, the Wilcoxon Rank Sum test, a nonparametric test, was used instead of a two-sample t-test to determine if the broodlines were statistically significantly different. The null hypothesis assumes "location shift is equal to zero," or simply, matching distributions with matching medians. Rejecting the 
null would indicate a shift in one distribution to the left or right, in other words, different medians.

Differencing, a data transformation method, was applied calculating the difference between consecutive data points as a method to stabilize the trend of the time series to observe variation and apply further analysis methods (Coghlan 2015). Once differenced, graphing the series alongside each other gives a picture of the variation between the even and odd year series and sets the data up for cumulative sum calculations. Percent change analysis is a view of change from year to year after differencing, returning positive values in the case that the following year is greater, and negative values in the case that it is smaller (Coghlan 2015).

The cumulative sum method of time series analysis is a method for observing rate of change. By adding successive years to the existing total of those before, a picture of the increase in abundance specifically as it changed over time was established. The slopes of these lines of rate of change were then compared, showing differing rates where they exist.

Autocorrelation testing determined if previous values in the series strongly determined the following data points. This method provides the coefficient of correlation between values in a time series, which can be measured against a confidence interval of 0.05. The formula is calculated at a particular lag, indicating how far apart the data points are. In this case, a lag value of one will compare a year's abundance value to the previous year. Significant values indicate data points, years, which are significant predictors of other points. Values that fall to zero indicate a lack of correlation or significant prediction 
of other values. Series that demonstrate serial correlation will demonstrate large alternating positive and negative fluctuations or values decreasing very slowly to zero over time. Autocorrelation analysis was applied to the entire dataset and to each broodline dataset. 


\section{Results}

The odd year broodline produces regularly higher values for the number of fish caught, with an average value roughly nine million fish per season higher than that of the even year broodline (Figure 3). Additionally, each broodline has increased in abundance over the fifty-year data set; however the odd year abundance values have not only remained higher but increased more rapidly and consistently than the even year abundance values (Figure 4).

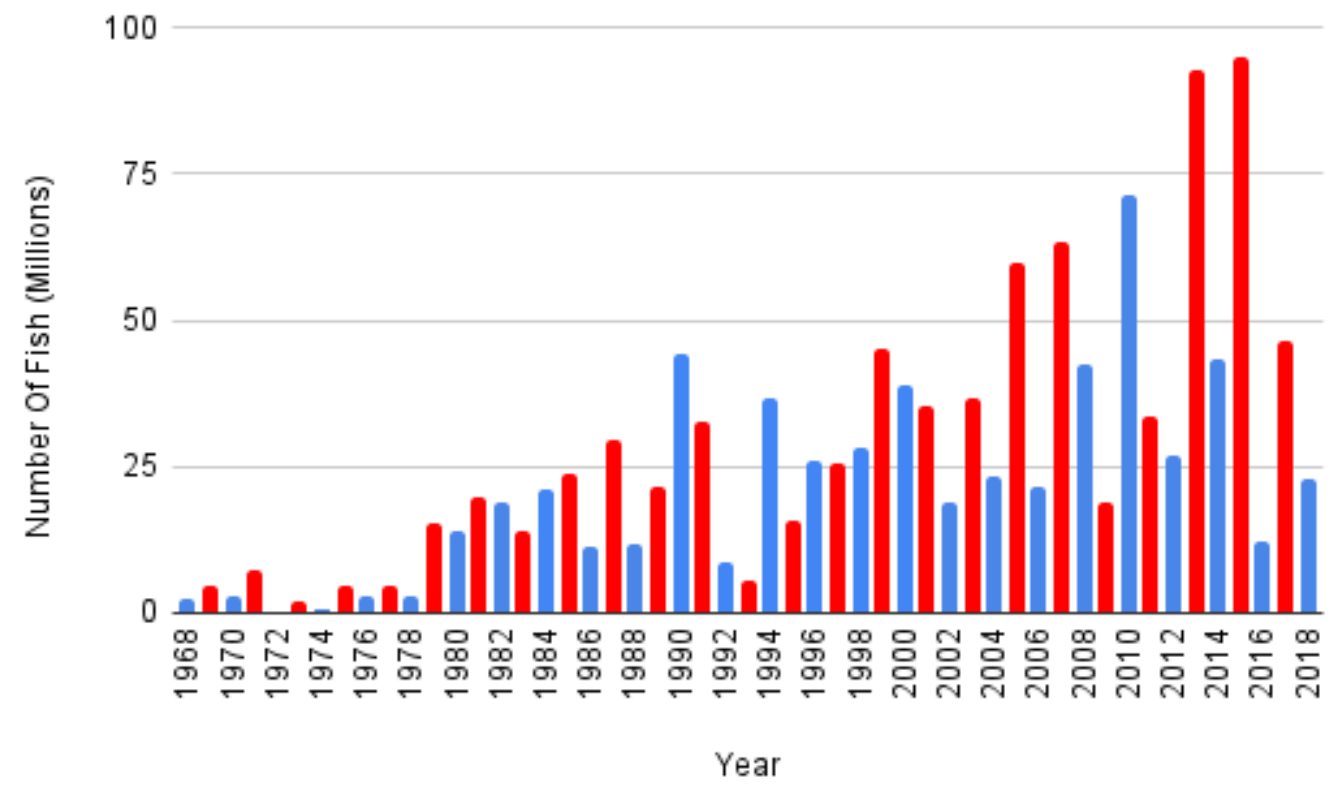

Figure 3. The full dataset of abundance indices, where even years are represented in blue and odd years are represented in red. 


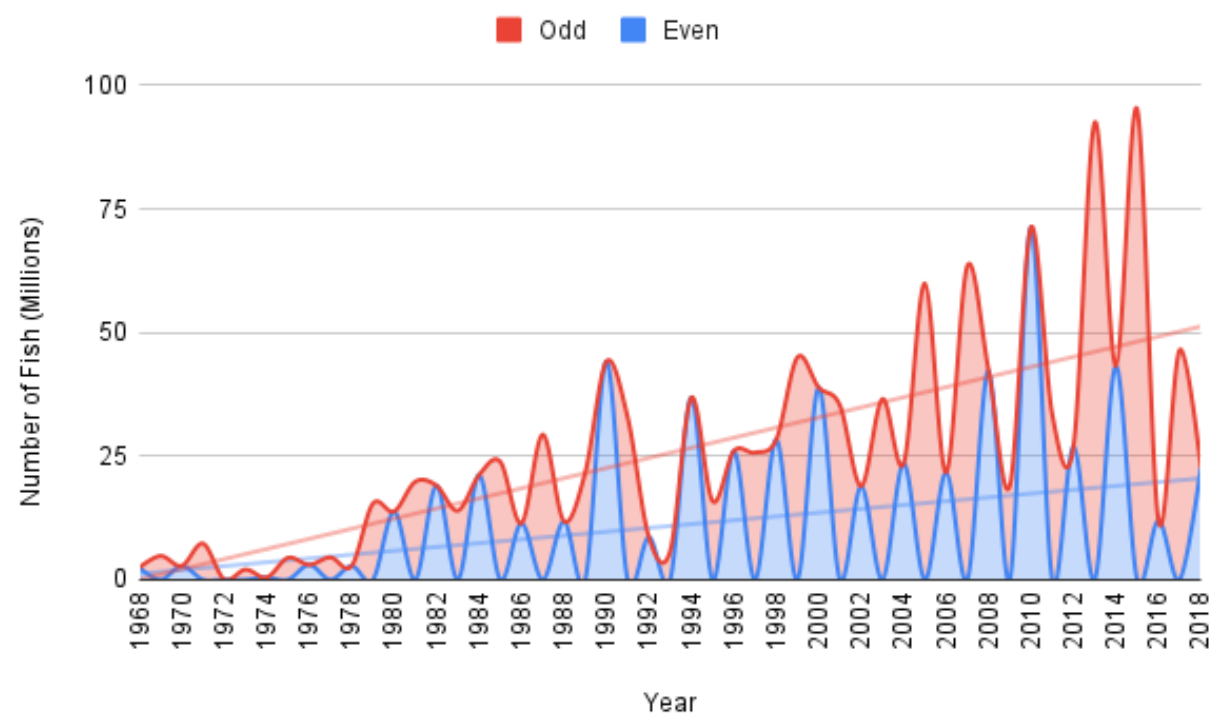

Figure 4. The abundance indices from 1969 to 2017, with trend lines showing the overall increase in million of fish caught.

Percent change values of the odd year broodline exhibit variation but are largely positive, indicating a trend upward from year to year (Figure 5). Negative values, which indicate a decrease from one year to the next, occur seven times in the twenty-six values calculated from the raw data. 


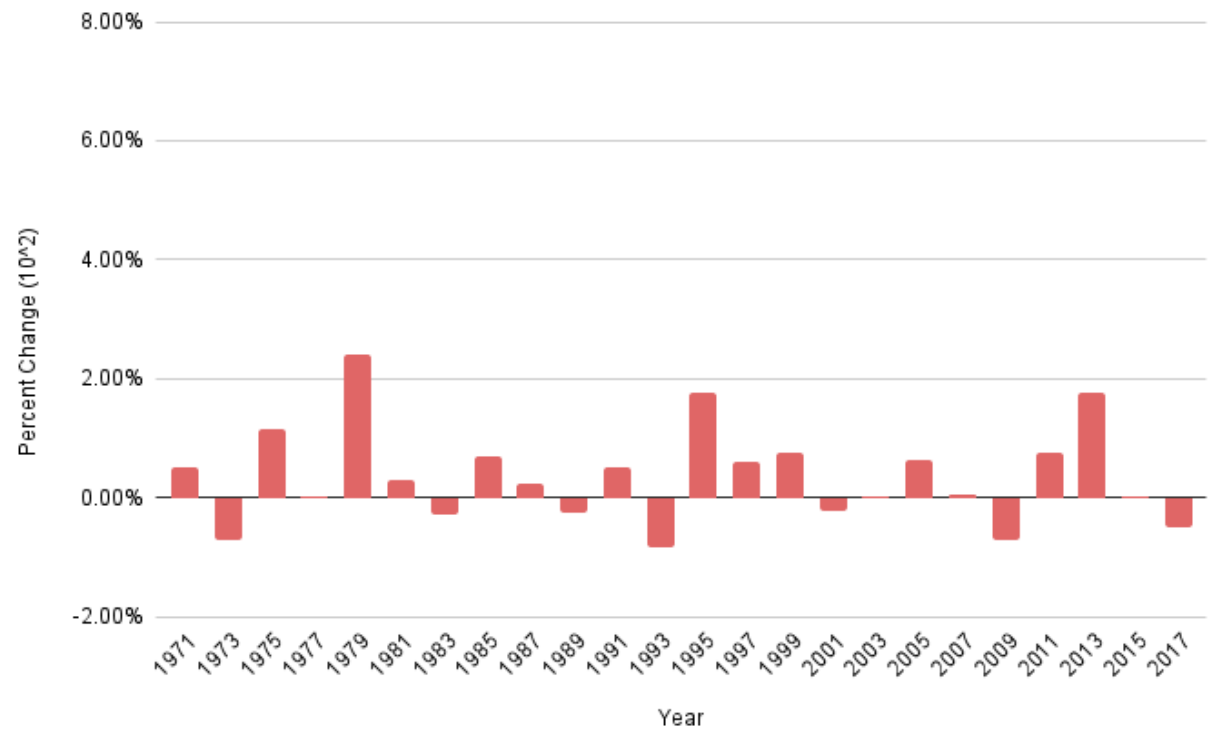

Figure 5. Percent change in the raw data of the odd year broodline, negative values indicating a downward trend in abundance and positive values indicating growth.

Percent change in the even year broodline reveals an extremely high degree of variation (Figure 6). The initial view is misleading due to an incredibly large spike following the record low fishing year in 1972. When measured on the same scale it is clear that even year fluctuations are greater than odd year fluctuations. There are nine negative values from a set of twenty-five percent change values, but many of the values are percent changes over $200 \%$, indicating an abundance index that may have doubled from a previous year, while remaining much lower than a corresponding odd year. While the average percent change value is positive, it comes out at $90.04 \%$ due to these very large shifts between years. 


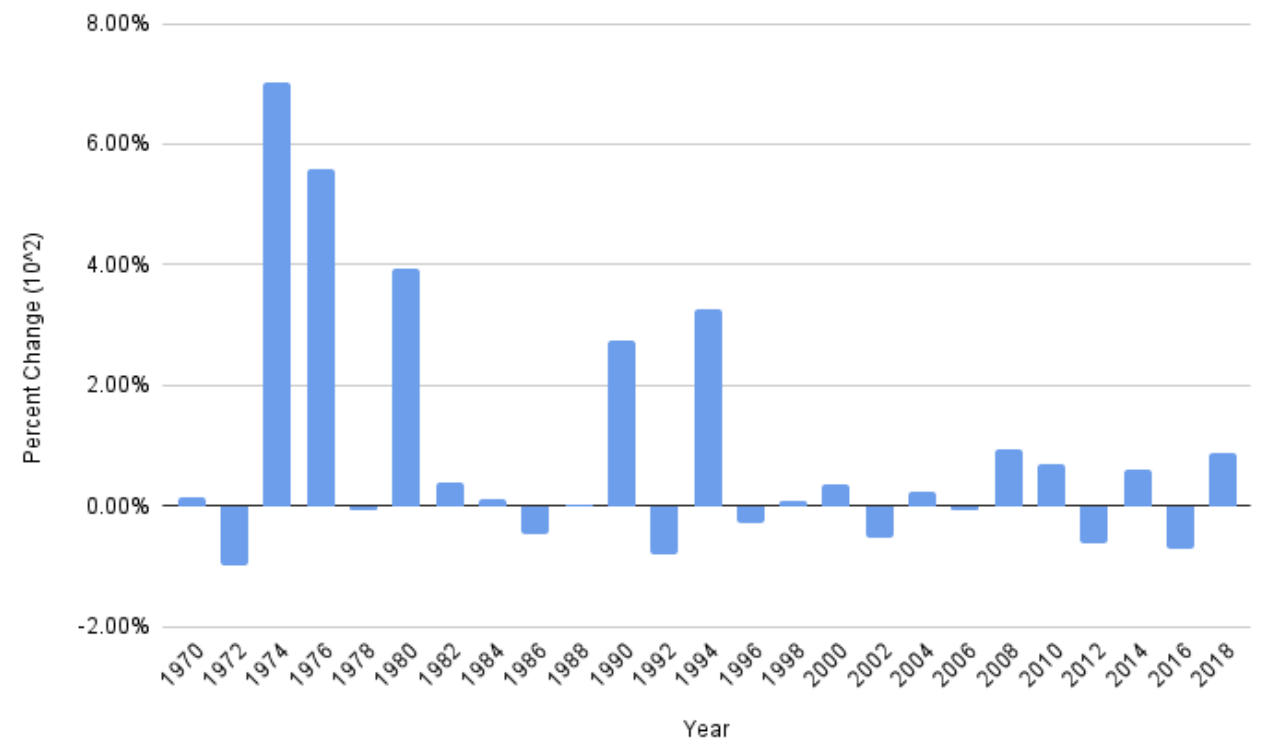

Figure 6. Percent change in the raw data of the even year broodline, negative values indicate a downward trend in abundance and positive values indicate growth. 1972 was a record low year with a catch of 57,000 fish.

Observing the percent change of the dataset from even to odd year emphasizes the dramatic shifts in abundance even more than the individual broodlines (Figure 7). In the case of the shift from the record low of $1972(57,000$ fish) to $1973(2,065,844$ fish) is a $3,518 \%$ increase that cannot even be measured on the same scale as the majority of the percent change values (Figure 7; 1973). 


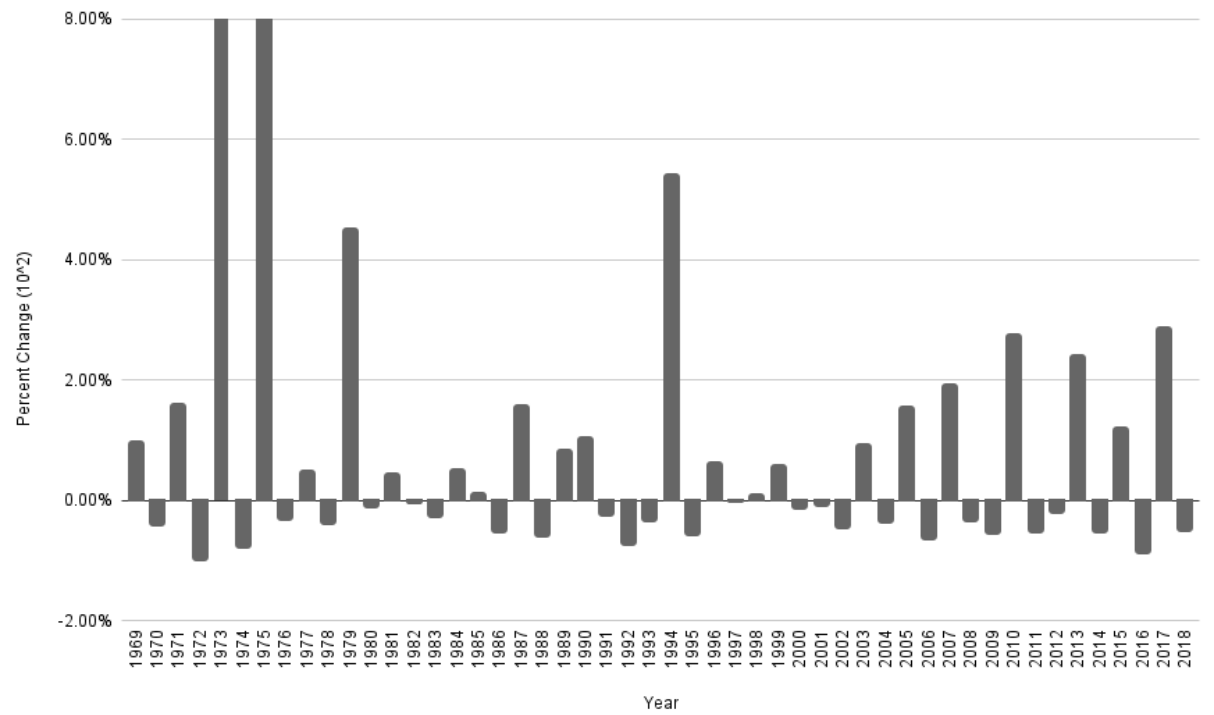

Figure 7. Percent change values for the dataset from 1968-2018, odd years typically marking a large increase from the prior even year.

A side-by-side comparison of these differenced series shows they are obviously not the same (Figure 8). However, application of the Wilcoxon Rank Sum test for nonnormally distributed data both before and after differencing gives a p-value of 0.1 , clearly greater than 0.05 , indicating that statistically the broodlines are not significantly different. With this, the null hypothesis $\left(\mathrm{H}_{1}\right.$ : $\mathrm{A}=\mathrm{B}$. Data shift is equal to zero) is accepted. 


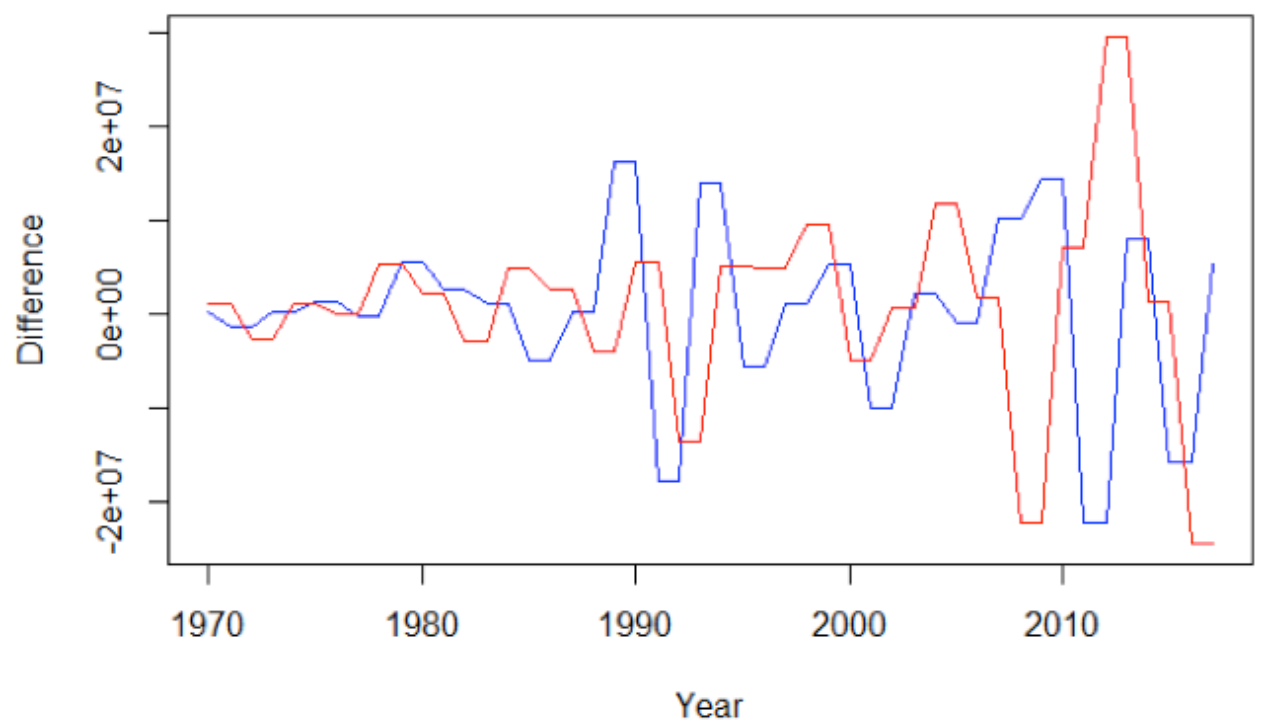

Figure 8 . Side by side view of the differenced broodline datasets, now stationary, achieved by subtracting the previous year from the current one.

The cumulative sum method is a way to visualize and analyze the change over time in the series. Once established, the cumulative sums of the series can be compared. Visually this provides an assessment of overall values and how they make up the abundance index and the individual broodlines (Figure 9; Figure 10). 


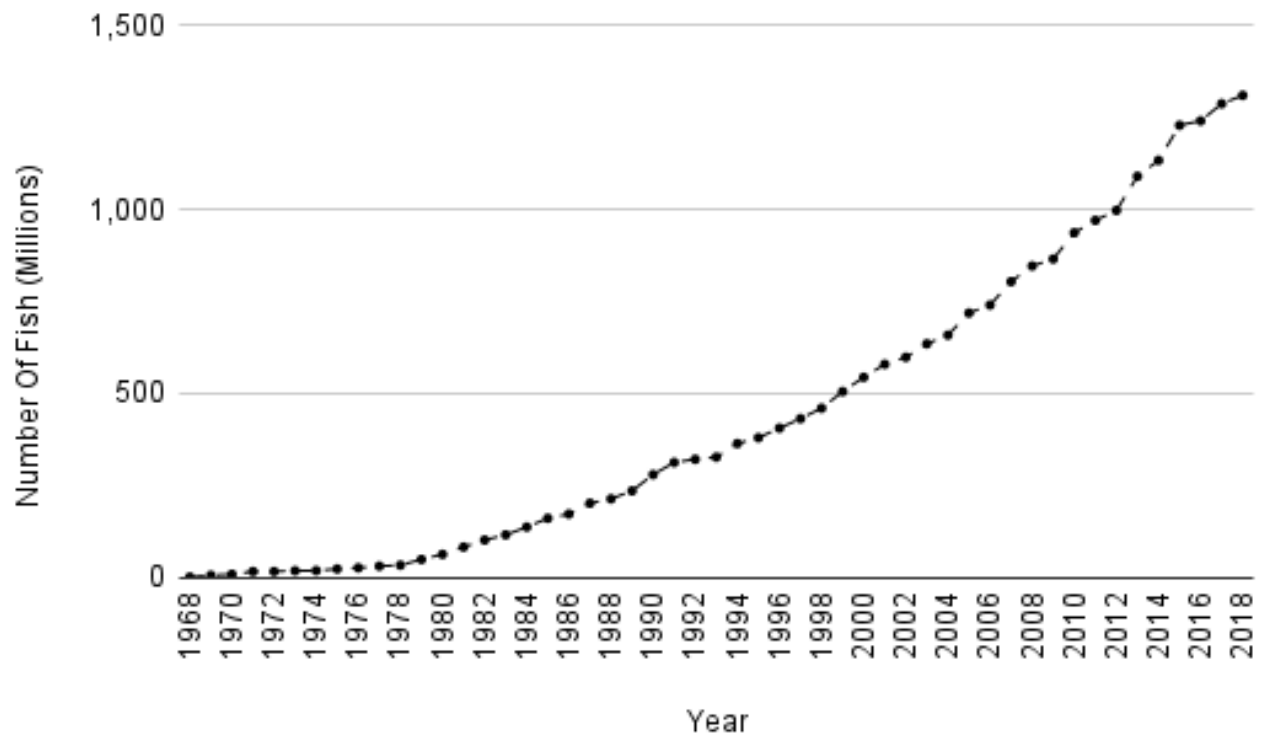

Figure 9. The cumulative sum of the abundance index, achieved by adding each year to the sum of the previous.

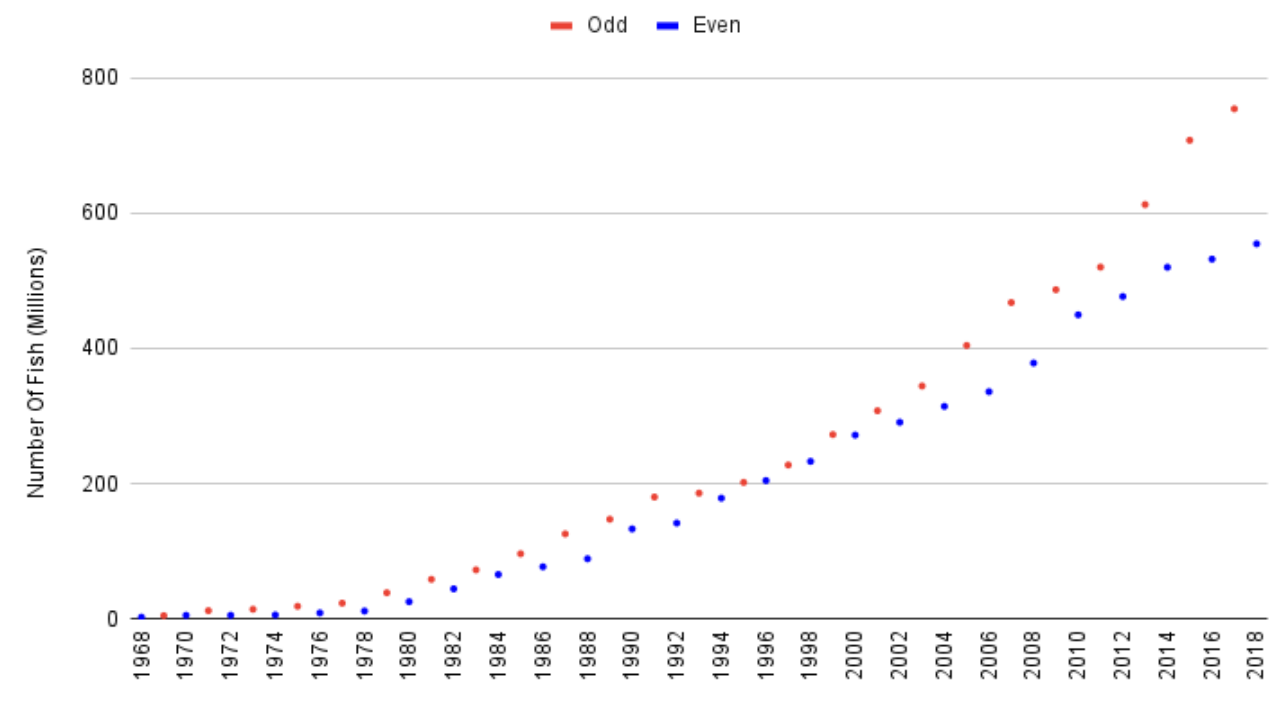

Figure 10. The cumulative sums of the even broodline in blue and the odd broodline in red.

Visualization of the cumulative sums as straight lines gives a more obvious indication of slope and overall rate of change (Figure 11; Table 1). Though the distributions are not 
statistically significantly different by the Rank-Sum test, the slopes of the cumulative sums of the broodlines are different, indicating that there are differences in the rate of growth. The comparison of the slope equations specifically shows a greater rate of change in the odd year broodline.

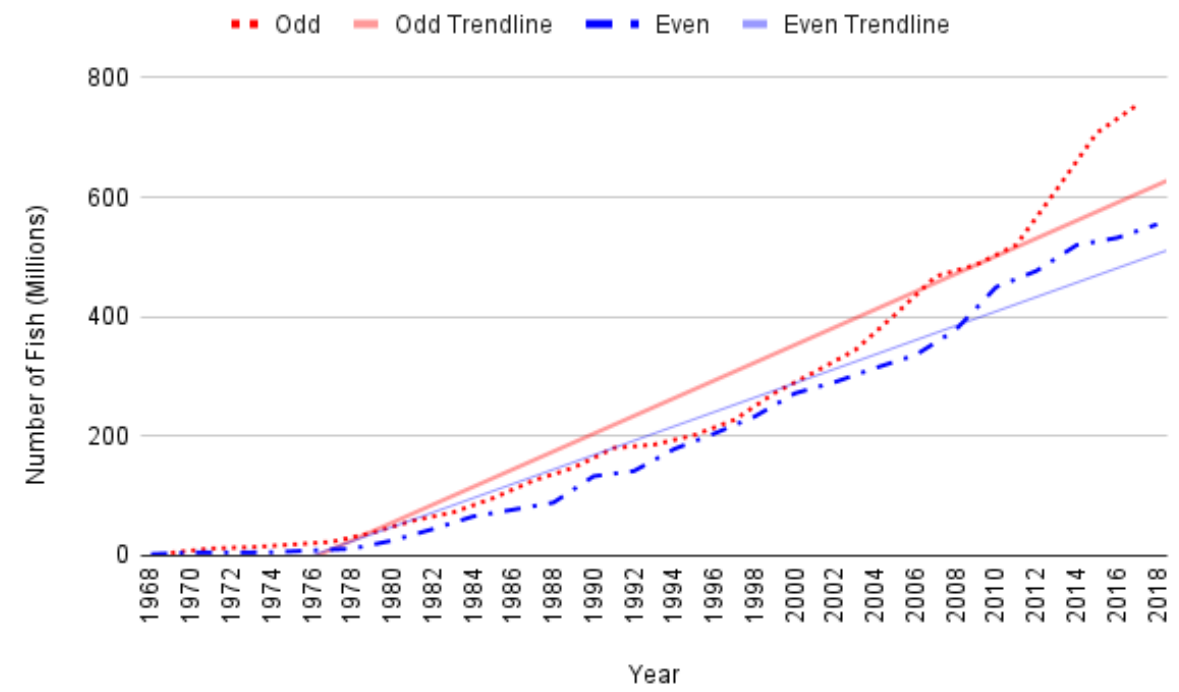

Figure 11. The cumulative sums of the even, in blue, broodline and the odd, in red, broodline, including trendlines representing the rate of change.

Table 1. Slopes of the cumulative sum lines in the datasets.

\begin{tabular}{|l|l|}
\hline Dataset & Slope (Slope-Intercept Form) \\
\hline Abundance from 1968-2018 & $26128908 \mathrm{x}-51419238658$ \\
\hline Even Year Broodline 1968-2018 & $1043804 \mathrm{x}-21731754222$ \\
\hline Odd Year Broodline 1969-2017 & $15613054 \mathrm{x}-30737275690$ \\
\hline
\end{tabular}

The difference in increase between the odd year broodline and the even year broodline is clear as it progresses along the time frame. The even year broodline 
evidences more variation in the differenced data (Figure 8) as well as in dramatic fluctuations of the percent change values recorded across the dataset (Figure 7). In looking at the results of the percent change and the comparison of slopes, there is a significant difference from the odd year broodline when viewed under the same tests. The odd year broodline had more consistent increases (Figure 3), higher abundance values (Figure 4) and a cumulative sum that slopes upward more sharply (Figure 11), indicating that the changes in abundance happen at an increased rate.

Finally, to test the hypothesis that yearly abundance is not determined by the previous year's abundance, autocorrelation analysis was employed. The results here of the autocorrelation function (ACF) at lag one demonstrated that there is little autocorrelation, also known as serial correlation, of significance (Figure 12). The spike at year zero is always 1.0 as it correlates with itself, but following values decrease to zero. Autocorrelation analysis run on the individual broodline datasets revealed only slightly more significance, demonstrating that while the preceding breeding year for the broodline may have an impact, the effect is not strongly correlated with future points in the dataset (Figure 13; Figure 14). This result accepts the null hypothesis $\left(\mathrm{H} 2_{0}\right.$ : Data points at lag 1 do not exhibit serial correlation.) 


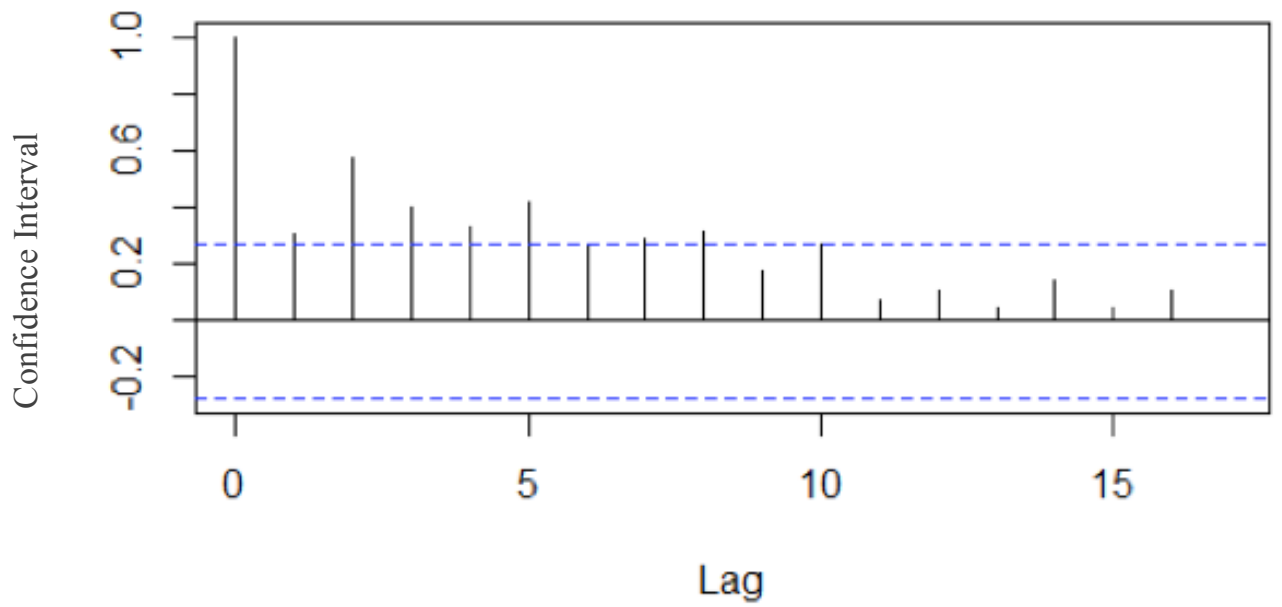

Figure 12. Autocorrelation of the abundance dataset at lag 1, for the first 18 years. Values in the data after this become even smaller and insignificant.

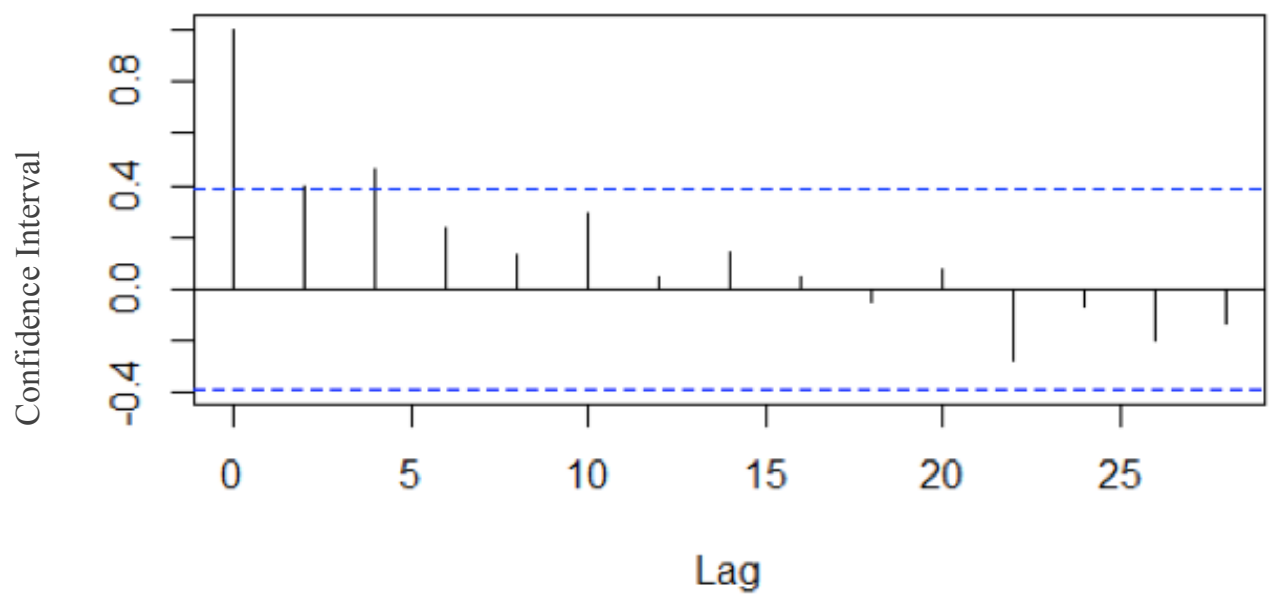

Figure 13. The results of autocorrelation tests on even data, where the dotted blue lines represent a 0.05 confidence interval. 


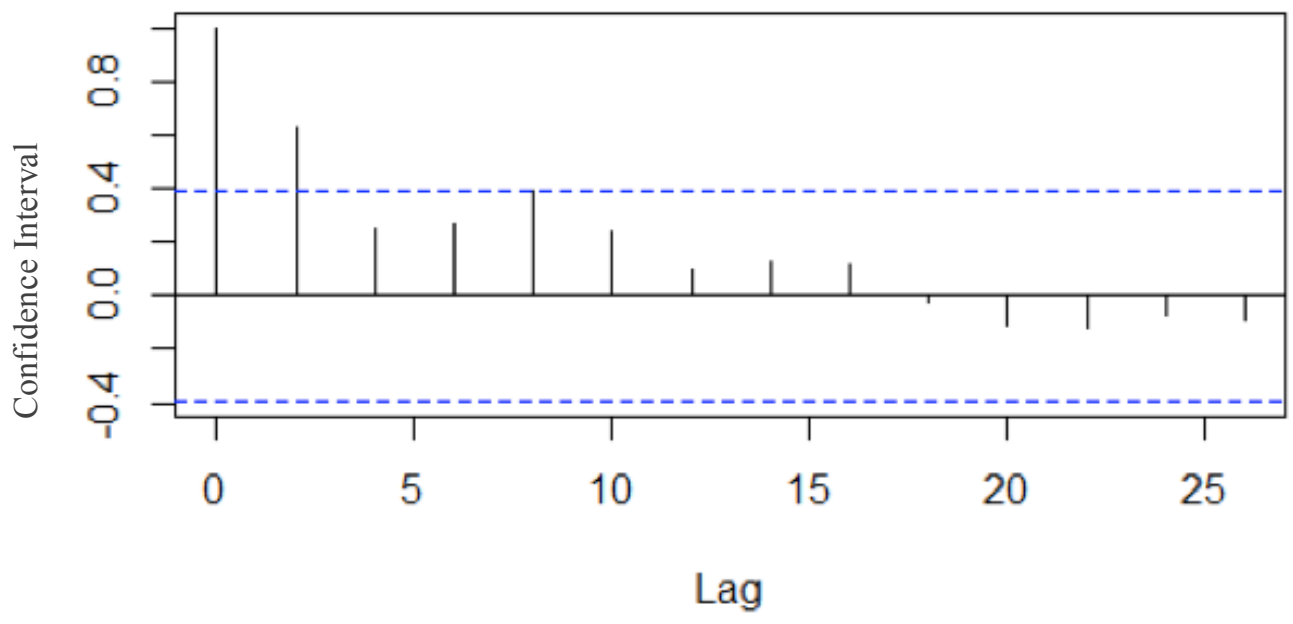

Figure 14. Autocorrelation of odd year raw data, where the dotted blue lines represent a 0.05 confidence interval. 


\section{Discussion}

This research examined the abundance of the two pink salmon broodlines in Prince William Sound to assess whether there is a difference in the catch abundance between even and odd year broodlines, a difference that was strongly suspected (Groot and Margolis 1991), but which needed to be confirmed. While the catch levels of both broodlines have been increasing over time, there is still a marked difference between the odd and even year broodlines. The analysis showed that the odd year abundance increased more rapidly and at larger values than the even year abundance. This has been established in other locations including parts of British Columbia (Groot and Margolis 1991; Irvine et al. 2014).

Paired with observation of current events and policy in the region, this analysis supports assumptions that can be made following the disastrous fishing season in 2016 as compared to the record-breaking seasons in 2013 and 2015 (Botz and Russell 2017). Though it is not verifiable that odd year broodline abundance increases because of even year abundance decreasing or becoming unstable, it is apparent that the two are happening along the same time frame.

Yearly abundance was not found to be dependent on the previous year's abundance, indicating the near-independence of hatches from one year to the next. This result seems counterintuitive when discussing a single species, as the previous breeding seasons should have an impact on those following. In order for this to be the case, there must be some outside factor or factors impacting the relationship between parent generations and their offspring. Because Prince William Sound has such intensive hatchery production 
and release, there may be such a contribution of fish from hatcheries that there is no longer a direct relationship between each generation's populations.

With instability in fish populations comes instability in the industry they support. In the case of the pink salmon fishery in PWS, the hatchery-released fish are intended to bolster wild populations and help to guard fishermen and processors from the consequences of a very poor season among wild-spawning salmon. However, when this is unsuccessful, such as in the disastrous 2016 season, it leaves not only independent fishermen in economic distress, but taxes the state further to make up the difference in supporting aquaculture associations such as PWSAC. In very dire situations, not only is the economic gain of the season threatened, but also employment opportunity in the industry going forward is in jeopardy. A processing company or fishing vessel that anticipates a very low-yield season will hire fewer employees to cut down on the risk of paying for unnecessary labor. These factors combine to create even more economic stress on individuals for whom the seasonal fishing industry may be their only source of income for the year.

Many possibilities exist for why the even year broodline demonstrates a lesser rate of growth, as well as extreme variation within itself. In some regions, such as the Fraser river, there are no or very few naturally occurring even year spawning salmon, while in Bristol Bay there are no naturally occurring odd year spawning salmon (Groot and Margolis 1991). Based on the geographic distribution, some researchers suggest that water temperature favors one broodline over the other (Irvine and Fukuwaka 2011; Radchenko, Temnykh and Lapko 2007). This seems like one of the most likely factors, 
very possibly in conjunction with other environmental and genetic changes. As warmer ocean temperatures push cold-water species further north, a broodline that favors cold water is going to be less successful.

Other possibilities include that introduction and widespread use of hatchery stock to augment wild spawning populations. Though the intent in releasing hatchery-raised stocks is to recapture all of them at maturity, there is always a degree of hatchery escapement (Brenner, Moffitt and Grant 2012). Additionally, hatchery stocks that survive to spawn naturally have low rates of breeding success when compared to wild spawning salmon (Brenner, Moffitt and Grant 2012; Hillborn and Eggers 2000).

Further Research

The overall trend from 1968 to 2018 data showed increasing catch numbers due to factors including increased hatchery fish contributions and improved fishing methods, years can be compared relative to those shortly before and after with reasonable certainty that these factors are constant. Further research could establish a view of catch effort standardization for the region by examining the overlap of fishing effort and improvements in technology or fishing methods. This may be difficult to examine because fishing days are determined by the state based on the presence of substantial populations, rather than the season opening and closing at predetermined dates, making days in the season a function of fish population as opposed to fish captured being a function of days in the season. Further study is also needed to establish whether even year runs are not, in fact, naturally successful in Prince William Sound, but instead the result of hatchery stocks straying into spawning streams. 


\section{References}

"Alaska Habitat Management Guide, Southcentral Region, Volume 1: Life Histories and Habitat Requirements of Fish and Wildlife." 1985. Juneau: Alaska Department of Fish and Game Division of Habitat.

Alaska Department of Fish and Game. 2018a. 2019-2021 Prince William Sound Area Commercial Salmon Fishing Regulations.

\section{. 2018b. 2016 Pink Salmon Disaster Spending Plan. Department of Fish and Game.}

Alexander, Richard D, and Robert S Bigelow. 1960. "Allochronic Speciation in Field Crickets, and a New Species, Acheta Veletis,” Evolution 14, 14, no. 3: 334-46.

Amoroso, Ricardo O, Michael D Tillotson, and Ray Hilborn. 2017. "Measuring the Net Biological Impact of Fisheries Enhancement: Pink Salmon Hatcheries Can Increase Yield, but with Apparent Costs to Wild Populations," Canadian Journal of Fisheries and Aquatic Sciences 74, 74, no. 8: 1233-42.

Blankenship, H Lee, and Kenneth M Leber. 1995. “A Responsible Approach to Marine Stock Enhancement.” In , 15:167-75. 15.

Botz, Jeremy, and Charles Russell. 2017. "Prince William Sound Area Commercial Salmon Fisheries: A Report to the Alaska Board of Fisheries."

Buklis, Lawrence S. 1999. "A Description of Economic Changes in Commercial Salmon Fisheries in a Region of Mixed Subsistence and Market Economies," Arctic, , 40-48.

Campbell, Robert A. 2015. "Constructing Stock Abundance Indices from Catch and Effort Data: Some Nuts and Bolts.” Fisheries Research 161. ScienceDirect.

Clark, John H, Andrew McGregor, Robert D Mecum, Paul Krasnowski, and Amy M Carroll. 2006. "The Commercial Salmon Fishery in Alaska," Alaska Fishery Research Bulletin 12, 12, no. 1: 1-146.

Coghlan, Avril. 2015. “A Little Book of R for Time Series,” Disponıvel em: https://media.readthedocs.org/pdf/a-little-book-of-r-for-time-series/latest/a-littlebookof-r-for-time-series.pdf $\underset{i}{ }$. Acesso em 10, 10.

Groot, Cornelis, and Leo Margolis. 1991. Pacific Salmon Life Histories. UBC press. 
Heard, William R. 2001. “Alaska Salmon Enhancement: A Successful Program for Hatchery and Wild Stocks," Ecology of aquaculture species and enhancement of stocks. 149.

Heard, William R. 2012. "Overview of Salmon Stock Enhancement in Southeast Alaska and Compatibility with Maintenance of Hatchery and Wild Stocks," Environmental Biology of Fishes 94, 94, no. 1: 273-83.

Hilborn, Ray. 2007. "Defining Success in Fisheries and Conflicts in Objectives," Marine Policy 31, 31, no. 2: 153-58.

Hilborn, Ray, Trevor A. Branch, Billy Ernst, Arni Magnusson, Carolina Minte-Vera, Mark D. Scheuerell, and Juan L. Valero. 2003. "State of the World's Fisheries," Annual Review of Environment and Resources 28, 28, no. 1: 359-99.

Hilborn, Ray, and Doug Eggers. 2000. "A Review of the Hatchery Programs for Pink Salmon in Prince William Sound and Kodiak Island, Alaska," Transactions of the American Fisheries Society 129, 129, no. 2: 333-50.

Holmes, E. E., M. D. Scheuerell, and E. J. Ward. 2020. Applied Time Series Analysis for Fisheries and Environmental Sciences. 2725 Montlake Blvd E., Seattle, WA 98112: NOAA Fisheries, Northwest Fisheries Science Center.

Hyndman, Rob J, and George Athanasopoulos. 2018. Forecasting: Principles and Practice. OTexts.

Irvine, James R, and Masa-aki Fukuwaka. 2011. "Pacific Salmon Abundance Trends and Climate Change," ICES Journal of Marine Science 68, 68, no. 6: 1122-30.

Loring, Philip A. 2013. "Alternative Perspectives on the Sustainability of Alaska's Commercial Fisheries," Conservation Biology 27, 27, no. 1: 55-63.

Maunder, Mark N, and André E Punt. 2004. "Standardizing Catch and Effort Data: A Review of Recent Approaches," Fisheries research 70, 70, no. 2-3: 141-59.

McDowell Group. 2018. "Economic Impact of Alaska's Salmon Hatcheries." Anchorage, Alaska: McDowell Group. http://www.mcdowellgroup.net/wpcontent/uploads/2018/10/economic-impact-of-alaskas-salmon-hatcheries.pdf.

Noakes, Donald J, and Richard J Beamish. 2011. "Shifting the Balance: Towards Sustainable Salmon Populations and Fisheries of the Future," Sustainable Fisheries: Multi-Level Approaches to a Global Problem, , 23-50. 
Poe, Aaron J, and Randy Gimblett. 2017. Sustaining Wildlands: Integrating Science and Community in Prince William Sound. University of Arizona Press.

Porszt, Erin J, Randall M Peterman, Nicholas K Dulvy, Andrew B Cooper, and James R Irvine. 2012. "Reliability of Indicators of Decline in Abundance," Conservation Biology 26, 26, no. 5: 894-904.

Radchenko, Vladimir I, Olga S Temnykh, and Viktor V Lapko. 2007. "Trends in Abundance and Biological Characteristics of Pink Salmon (Oncorhynchus Gorbuscha) in the North Pacific Ocean," North Pacific Anadromous Fish Commission Bulletin 4, 4: 7-21.

Regier, Peter, Henry Briceño, and Joseph N. Boyer. 2019. “Analyzing and Comparing Complex Environmental Time Series Using a Cumulative Sums Approach," MethodsX 6, 6: 779-87.

Ruggerone, Gregory T, and Jennifer L Nielsen. 2004. "Evidence for Competitive Dominance of Pink Salmon (Oncorhynchus Gorbuscha) over Other Salmonids in the North Pacific Ocean," Reviews in Fish Biology and Fisheries 14, 14, no. 3: 371-90.

Schoen, Erik R, Mark S Wipfli, E Jamie Trammell, Daniel J Rinella, Angelica L Floyd, Jess Grunblatt, Molly D McCarthy, Benjamin E Meyer, John M Morton, and James E Powell. 2017. "Future of Pacific Salmon in the Face of Environmental Change: Lessons from One of the World's Remaining Productive Salmon Regions," Fisheries 42, 42, no. 10: 538-53.

Shumway, Robert H, and David S Stoffer. 2017. Time Series Analysis and Its Applications: With R Examples. Springer.

Skud, Bernard Einar. 1982. "Dominance in Fishes: The Relation between Environment and Abundance," Science 216, 216, no. 4542: 144-49.

Stergiou, K I, and E D Christou. 1996. "Modelling and Forecasting Annual Fisheries Catches: Comparison of Regression, Univariate and Multivariate Time Series Methods," Fisheries Research 25, 25, no. 2: 105-38.

Stopha, Mark. 2016. “Alaska’s Private Non-Profit Hatchery Program.” Alaska Fish and Wildlife News.

Tarpey, Carolyn M, James E Seeb, Garrett J McKinney, William D Templin, Alexander Bugaev, Shunpei Sato, and Lisa W Seeb. 2018. "Single-Nucleotide Polymorphism Data Describe Contemporary Population Structure and Diversity in Allochronic Lineages of Pink Salmon (Oncorhynchus Gorbuscha)," Canadian Journal of Fisheries and Aquatic Sciences 75, 75, no. 6: 987-97. 
Taylor, Rebecca S, and Vicki L Friesen. 2017. "The Role of Allochrony in Speciation," Molecular ecology 26, 26, no. 13: 3330-42.

Townend, James. 2002. Practical Statistics for Environmental and Biological Scientists. Aberdeen, UK: John Wiley \& Sons.

Vega, Stacy L, Jeremy Botz, Stormy Haught, and Charles W Russell. 2019. 2017 Prince William Sound Area Finfish Management Report. Alaska Department of Fish and Game, Division of Sport Fish, Research and ....

Wertheimer, Alex C, William R Heard, J M Maselko, and William W Smoker. 2004. "Relationship of Size at Return with Environmental Variation, Hatchery Production, and Productivity of Wild Pink Salmon in Prince William Sound, Alaska: Does Size Matter?," Reviews in Fish Biology and Fisheries 14, 14, no. 3: 321-34.

Ye, Yimin, and Darren Dennis. 2009. "How Reliable Are the Abundance Indices Derived from Commercial Catch-Effort Standardization?," Canadian Journal of Fisheries and Aquatic Sciences 66, 66, no. 7: 1169-78. 